genesis of the central nervous system ${ }^{12-14}$. Destruction of the internal limiting membrane system often causes and regularly accompanies the development of malformations of the central nervous system.

The possible relation between relative field area and proliferation intensity, and origin of the internal limiting membrane system in the process of induction are the matter of further investigation.

Department of Anatomy,

R. JELÍNEK

Department of Histology,

Charles University, Prague.

${ }^{1}$ Sauer, F., J. Comp. Neurol., 62, 377; 63, 13 (1935).

${ }^{2}$ Heidenhain, M. (1897) (quoted in ref. 4).

${ }^{3}$ Leboucq, G., Arch. Anat. micr., 10, 555 (1909).

${ }^{4}$ Hoven, H., Arch. Biol. (Paris), 25, 427 (1910).

${ }^{5} \mathrm{His}, \mathrm{W} .$, Abh. mat. physic., Classe d. $k$. Sächs. ges. Wissen., 15, 313 (1889).

- Fujita, S., Nature, 185, 702 (1960).

'Sotelo, J., and Trujillo-Cénoz, D., Z. Zellforsch., 49, 1 (1958).

${ }^{8}$ Bellairs, R., Proc. Fifteenth Intern. Cong. Zoology, London, 610 (1958).

${ }^{9}$ Blechschmidt, E., $Z$. Anat. EntwGesch., 121, 434 (1960).

${ }^{10}$ Tennyson, V., Anat. Rec., 142, 285 (1962).

${ }^{11}$ O'Rahilly, R., Anat. Rec., 142, 263 (1962).

${ }^{12}$ Klika, E., and Jelinek, R., Ceskoslovenská morfologie, 10, 114 (1962).

${ }_{13}$ Jelínek, R., and Doskocil, M., Ceskoslovenská morfologie, 10, 402 (1962). 14 Jelínek, R., and Klika, E., Pokusná morfogenese nekterych vyvojorych

\section{Another Variable to be observed in Autoradiographs}

Autoradiography is a technique which reveals the sites of radioactivity in an object by means of a photographic emulsion. The object is brought into close contact with the emulsion and after a suitable period of time the emulsion is processed by photographic development. In such a preparation the sites of radioactivity are indicated by the presence of silver grains in the emulsion. At present, regions of an autoradiograph are regarded as different if the densities of their silver grains, in terms of some attribute of the object, are different. It may be possible to use another property of the grains to show that regions are different. This property is the way the grains are distributed in clusters.

The silver grains in autoradiographs of biological tissues prepared for light microscopy are not all present as single grains; some are present in clusters. The clusters can be arranged in sizes according to the number of grains they contain. It is possible to decide how many grains are in a cluster by examination of its outline. The number of clusters of each size can be counted over one area if a suitable micrometer is in the ocular of the microscope. When all the grains have been counted in one area a table of the frequency with which they are present in each size of cluster can be prepared.

Consider the hypothetical situation in which an isotope is present in a layer on a microscope slide and the isotope is distributed at perfectly regular intervals in the layer. It is possible for all the tracks of emission from the isotope to be only just separate. If this were so the frequency with which grains in the autoradiograph occurred in the various size of cluster would be determined by: (1) the thickness of the layer containing the isotope; (2) the ability of the layer to filter the emission; (3) the energy spectrum of the emission; (4) the thickness of the photographic emulsion; (5) the way in which the halide crystals are packed in the emulsion; (6) the number of halide crystals per unit area of emulsion; (7) the size of the halide crystals; (8) the number of developed grains per unit area.

Now consider the hypothetical situation in which the isotope is concentrated in small particles which are distributed at regular intervals in the layer. If the number of grains per unit area is the same as before, then the tracks of the emission must overlap. The frequency of single grains is decreased and that of clusters increased in comparison to their frequencies when the distribution of the isotope is perfectly even. The extent of the effect would be determined by the amount of the isotope in each particle and the size of the particles.

In practice the variations inherent in the technique are controlled best when observations on clusters are made under the following conditions: (1) regions of the same tissue section are compared which have the same number of grains per unit area; (2) the emulsion is affected by a single emission; (3) when more than one section is used, they should be on one microscope slide, covered by a single continuous layer of emulsion, and processed together.

If these precautions are taken, any difference in the frequency with which grains occur in the various sizes of cluster will reflect a difference in the distribution of the isotope in the section. With short-range emissions, like that of tritium, the greatest change can be expected in the frequencies with which grains are present as single grains and triple grain clusters.

Observations on this variable have been made in an experiment on the incorporation of tyrosine into the growing hair of rats. The tyrosine was generally labelled with tritium. Autoradiographs prepared from 2 rats killed $30 \mathrm{~min}$ after injection of the labelled tyrosine show three regions of the hair cortex over which the number of grains per unit area is the same. The three regions are the matrix of the hair bulb, the cortex of the upper bulb at the level of the top of the hair papilla, and the cortex just below the level of its complete keratinization. As a different process is performed in the cells at each of these sites it is reasonable to expect that the incorporation of tyrosine might be carried out in different manners. A table of the frequencies with which the grains are present in the sizes of cluster up to triple grains was prepared for each of the three levels. This was done for three hairs in each animal. The results from all the hairs are similar to those shown in Table 1. The percentage of single grains is lower for the shaft than for the matrix and upper bulb. The percentage of grains in clusters of three is higher for the shaft than for the matrix and upper bulb. The percentage of grains in clusters of two is similar for all three levels. No difference is apparent between the frequencies of the matrix and the upper bulb.

\begin{tabular}{lcccc}
\multicolumn{4}{c}{ Table 1 } & \\
& Matrix & Upper bulb & Shaft \\
Percentage of single grains & 40 & 45 & 24 \\
Percentage of grains in cluster of 2 & 22 & 35 & 25 \\
Percentage of grains in cluster of 3 & 17 & 8 & 37
\end{tabular}

The percentage of the total number of grains present in the size of cluster indicated in three regions of one growing hair.

The constant difference between the shaft and the other regions in the six hairs is shown to be significant at the 5 per cent level $(P=0.016)$ by the sign test. It is concluded that the labelled tyrosine incorporated into the hair cortex is distributed more evenly in the matrix and upper bulb than in the shaft just below the level of full keratinization. The difference could be produced by the presence of the isotope in different cell components, or the presence of the isotope in the same components under different spatial conditions. A full report and discussion of this experiment on protein synthesis will be published elsewhere.

The experiment illustrates the use of the method to show that regions of a tissue have incorporated a tracer in a different way at the same time interval after its administration. On suitable material it may be possible to demonstrate changes in the same region at different time intervals by this method.

I thank Prof. Leblond for his advice on the experiment with radioactive tyrosine which was performed at McGill University during the tenure of a Wellcome research travel grant. The work was supported by a grant from the Medical Research Council of Canada.

Anatomy School,

R. T. Stms

University of Cambridge. 